\title{
Brain radiation injury leads to a dose- and time-dependent recruitment of peripheral myeloid cells that depends on CCR2 signaling
}

Michael J. Moravan', John A. Olschowka², Jacqueline P. Williams ${ }^{1,3}$ and M. Kerry O'Banion ${ }^{2,4^{*}}$

\begin{abstract}
Background: Cranial radiotherapy is used to treat tumors of the central nervous system (CNS), as well as nonneoplastic conditions such as arterio-venous malformations; however, its use is limited by the tolerance of adjacent normal CNS tissue, which can lead to devastating long-term sequelae for patients. Despite decades of research, the underlying mechanisms by which radiation induces CNS tissue injury remain unclear. Neuroinflammation and immune cell infiltration are a recognized component of the CNS radiation response; however, the extent and mechanisms by which bone marrow-derived (BMD) immune cells participate in late radiation injury is unknown. Thus, we set out to better characterize the response and tested the hypothesis that C-C chemokine receptor type 2 (CCR2) signaling was required for myeloid cell recruitment following brain irradiation.

Methods: We used young adult C57BL/6 male bone marrow chimeric mice created with donor mice that constitutively express enhanced green fluorescent protein (eGFP). The head was shielded to avoid brain radiation exposure during chimera construction. Radiation dose and time response studies were conducted in wild-type chimeras, and additional experiments were performed with chimeras created using donor marrow from CCR2 deficient, eGFP-expressing mice. Infiltrating eGFP+ cells were identified and quantified using immunofluorescent microscopy.

Results: Brain irradiation resulted in a dose- and time-dependent infiltration of BMD immune cells (predominately myeloid) that began at 1 month and persisted until 6 months following $\geq 15$ Gy brain irradiation. Infiltration was limited to areas that were directly exposed to radiation. CCR2 signaling loss resulted in decreased numbers of infiltrating cells at 6 months that appeared to be restricted to cells also expressing major histocompatibility complex class II molecules.

Conclusions: The potential roles played by infiltrating immune cells are of current importance due to increasing interest in immunotherapeutic approaches for cancer treatment and a growing clinical interest in survivorship and quality of life issues. Our findings demonstrate that injury from brain radiation facilitates a dose- and timedependent recruitment of BMD cells that persists for at least 6 months and, in the case of myeloid cells, is dependent on CCR2 signaling.
\end{abstract}

Keywords: lonizing radiation, Late CNS radiation injury, Chimeric mice, Cell infiltration, Myeloid cells, CCR2

\footnotetext{
*Correspondence: kerry_obanion@urmc.rochester.edu

JPW and MKO are joint senior authors.

${ }^{2}$ Department of Neuroscience, University of Rochester School of Medicine

and Dentistry, Rochester, NY, USA

${ }^{4}$ Department of Neurology, University of Rochester School of Medicine and

Dentistry, Rochester, NY, USA

Full list of author information is available at the end of the article
} 


\section{Background}

Cranial radiotherapy is frequently utilized as part of the treatment of primary and secondary brain tumors, prophylaxis against clinically occult systemic malignancies, and for non-neoplastic diseases, such as arterio-venous malformations. However, the use of curative doses of radiation is often limited due to the potential for damage in the adjacent and surrounding normal brain tissue. Indeed, both acute and late/delayed radiation-induced sequelae can result in significant morbidity and/or mortality for patients, and thus, the pathogenesis of radiation injury in the normal central nervous system (CNS) tissue has been the subject of investigation for decades. Unfortunately, a thorough understanding of the underlying mechanisms, leading to mitigation strategies, has remained elusive.

Although identified as a frequent constituent of acute and late effects seen following radiation exposure, the precise contribution of neuroinflammation to their initiation and progression in the brain is not entirely clear. Work from our group [1-3] and others [4-6] has suggested a critical role for inflammation in the normal CNS response to radiation. Furthermore, use of antiinflammatory therapies, such as post-therapy steroids and NSAIDs, has demonstrated some beneficial outcomes, both in preclinical studies [7-9] and in patients [10-12]. However, the complex interplay between the various components of the inflammatory and immune systems has limited the ability of researchers to identify more specific targets that could effectively mitigate CNS normal tissue effects. For example, our group previously demonstrated acute and persistent increases in the numbers of CD3+ cells and CD11c+ cells in the CNS, as well as increased expression of $\mathrm{MHC}$ II, in response to radiation [3]. However, the development of specific and targeted therapeutic approaches would require identification of the origin of these CD11c+ and MHC II+ cells, since both populations could originate either from endogenous microglia or from leukocytes that have infiltrated from the periphery.

Multiple laboratories have investigated leukocyte infiltration in the CNS and have shown that bone marrowderived cells have the ability to enter and persist within the CNS, with a tremendous potential for transformation [13-22]. Importantly, the rate of leukocyte infiltration into the CNS has been shown to increase in the setting of inflammation and injury [21, 23-27], and an intriguing study, examining the infiltration of peripherally derived immune cells using bone marrow transplanted animals, suggested that leukocytes recruited to the CNS can develop a dendritic cell phenotype [17], although there is debate as to whether dendritic cells could also arise from resident microglia [28-30]. Burrell et al. showed that cranial irradiation led to a time- and dose-dependent infiltration of bone marrow-derived (BMD) cells, specifically in areas directly exposed to the radiation beam, starting at
7 days and persisting for up to 1 month post-irradiation. About $50 \%$ of the BMD cells located in the brain parenchyma stained for the microglial marker Iba-1, 7 days following radiation [31]. Only a very small number of the BMD cells were found to express smooth muscle cell markers, and none were found to express endothelial or other glial markers. It is unclear whether these cells persisted later than 1 month post-radiation or if they contribute to the CD11c+ cells we previously reported [3].

Recruitment of myeloid lineage cells into the injured CNS environment depends on the expression of endothelial activation markers, such as intracellular adhesion molecule-1 (ICAM-1) [32-34] and chemokine signaling, particularly through the C-C (motif) ligand-2 (CCL2)/CC chemokine receptor type 2 (CCR2) [35-37] and stromal cell-derived factor (SDF1)/CXCR4 pathways [38, 39]. The ICAM-1 and CCL2/CCR2 pathways have also been shown to play a role in the recruitment of dendritic cells into injured/inflamed tissues, including the brain [35, 40-43]. Significantly, previous studies from our laboratory have demonstrated increased messenger RNA (mRNA) levels of CCL2 and ICAM-1 following CNS radiation exposure at times as late as 6-12 months postirradiation [3, 33]. A recent study by Morganti et al. demonstrated an increase in the number of CD11b+/F480+/CX3CL1-/CCR2+ cells (assumed to be peripherally derived), a significant increase in the CCL2 protein level, and an increase in the ICAM-1 mRNA level in the brain at 7 days following 10 Gy of cranial irradiation, suggesting that CCR2 signaling is responsible for the recruitment of these cells [44]. Taking all these findings together, we have hypothesized that the time-dependent appearance of MHC II+ and CD11c+ cell populations observed following mouse brain irradiation in our previous work [3] is dependent on CCL2/CCR2 signaling.

To address this hypothesis, bone marrow chimera animals were created using marrow from animals engineered to constitutively express enhanced green fluorescent protein (eGFP) under the $\beta$-actin promoter and, following confirmation of chimerism, the animals underwent brain irradiation. In support of our hypothesis, radiation exposure resulted in a chronic, dose-dependent increase in the number of eGFP-expressing cells in the brain. Furthermore, chimeras created with CCR2-deficient, eGFP+ bone marrow demonstrated reduced infiltration levels of eGFP+ myeloid cells following CNS radiation, indicating the importance of CCR2 signaling in myeloid cell recruitment in this injury model.

\section{Methods}

\section{Animals}

This study was carried out in strict accordance with the recommendations in the Guide for the Care and Use of Laboratory Animals of the National Institutes of Health. 
Animal protocols were reviewed and approved by the University of Rochester Institutional Animal Care and Use Committee (Protocol Number: 2004-74). Male C57BL/6J (stock no. 000664), C57BL/6-Tg(CAG-EGFP)10sb/J (stock no. 003291), and B6.129S4-Ccr2 $2^{\text {tm1lfc } / J ~(s t o c k ~ n o . ~ 004999) ~}$ mice were purchased from The Jackson Laboratory at 8 to 10 weeks of age. Animals were housed 5 to a cage in temperature $\left(23 \pm 3^{\circ} \mathrm{C}\right)$ and light (12:12 light/dark) controlled rooms with free access to chow and water. Mice were routinely monitored for health issues and had no observable problems at the time of euthanasia.

\section{Bone marrow chimeras}

C57BL/6J mice were exposed to two 6 Gy doses of whole body irradiation, separated by $4 \mathrm{~h}$, using a ${ }^{137} \mathrm{Cs}$ source (J. L. Shepherd and Assoc.) at a dose rate of $1.9 \mathrm{~Gy} / \mathrm{min}$. The mice were unanesthetized, confined in customized plexiglass jigs, and placed on a slit collimator such that the radiation field included the entire mouse, with the head shielded in order to reduce the dose to the head to $15-20 \%$ of the unshielded area. Head shielding was used in order to minimize the split dose effect with respect to the subsequent brain exposures since we observed significant increases in the number of eGFP+ cells in the CNS of non-shielded animals compared to head-shielded animals following brain irradiation (Additional file 1: Figure S1). Indeed, other investigators also have found increased immune cell infiltration in bone marrow transplanted animals where the cranium was exposed to radiation as part of the transplantation process [26, 45]. Following the second dose of total body radiation, the mice were injected intravenously with $4 \times 10^{6}$ bone marrow cells harvested from the femurs and tibias of mice that constitutively express enhanced green fluorescent protein (eGFP) and then returned to the vivarium for 6 weeks, allowing for bone marrow reconstitution. To determine the role of CCR2 signaling, we used an identical procedure to create chimeric C57BL/6J mice reconstituted with bone marrow from eGFP-expressing mice that had been crossed with mice deficient for CCR2. In all studies, the degree of bone marrow reconstitution was confirmed by drawing peripheral blood prior to euthanasia. Flow cytometry was subsequently performed to confirm the percentages of eGFP+ cells expressing CD11b, B220, CD4, and CD8, representing monocytic, B cell, and $\mathrm{T}$ cell lineages, respectively.

\section{Brain irradiation}

For brain irradiation, mice were anesthetized (ketamine [90 $\mathrm{mg} / \mathrm{kg}$ ] and xylazine $[8 \mathrm{mg} / \mathrm{kg}$ ], administered intraperitoneally) then laid supine on the ${ }^{137} \mathrm{Cs}$ irradiator such that the brain volume between their eyes and ears was exposed using a $5-\mathrm{mm} \times 12.2-\mathrm{cm}$ collimator slit. This collimator provided a uniform field at a dose rate of $1.25 \mathrm{~Gy} / \mathrm{min}$ with sharp edges that fell to a dose rate of $0 \mathrm{~Gy} / \mathrm{min}$ within $2.5 \mathrm{~mm}$ of the slit edge. Animals $(n=$ 6 per group) were exposed to a dose range of 0 to $45 \mathrm{~Gy}$. After irradiation, mice were returned to the vivarium and supplied with laboratory diet and water ad libitum until the time of euthanasia. Mice in the time course study (35 Gy only) were euthanized at 1 day, 3 days, 7 days, 1 month, 3 months, or 6 months post-radiation; mice in the dose range and CCR2 chimera studies were euthanized at 6 months post-radiation.

\section{Tissue collection}

Immediately after euthanasia, mice were flushed intracardially with $10-15 \mathrm{ml}$ of a solution containing $2 \mathrm{IU} / \mathrm{ml}$ heparin and $0.05 \%$ sodium nitrite in $0.15 \mathrm{M}$ phosphate buffer (PB) and then perfused with $50 \mathrm{ml}$ of $4{ }^{\circ} \mathrm{C} 4 \%$ paraformaldehyde dissolved in $0.15 \mathrm{M} \mathrm{PB}(\mathrm{pH}=7.2)$. Brains were removed and post-fixed in $4 \%$ paraformaldehyde dissolved in $0.15 \mathrm{M} \mathrm{PB}(\mathrm{pH}=7.2)$ at $4{ }^{\circ} \mathrm{C}$ for 2 hours protected from light. Brains were then transferred to a $30 \%$ sucrose solution in $0.15 \mathrm{MPB}$ at $4{ }^{\circ} \mathrm{C}$, protected from light until equilibrated, and were then snap frozen in isopentane and stored at $-80^{\circ} \mathrm{C}$ until sectioning.

\section{Immunohistochemistry/immunofluorescence assays}

Brains were sectioned in the coronal plane at $30 \mu \mathrm{m}$ on a sliding knife microtome with a $-25{ }^{\circ} \mathrm{C}$ freezing stage. Sections were stored in cryoprotectant at $-20{ }^{\circ} \mathrm{C}$ until further processing. Visualization of antibody-bound sections for immunohistochemistry (IHC) was performed using biotinylated secondary antibodies, avidin-biotin complex (Elite), and 3,3-diaminobenzadine (DAB) substrate kit (Vector Laboratories). The following primary antibodies were utilized: mouse MHC class II I-A ${ }^{\mathrm{b}}$ (BD Pharmingen, 1:2000); Iba-1 (Wako, 1:5000); ICAM-1 (AbD Serotec, 1:2000); rat anti-CD3 (AbD Serotec, 1:4000); hamster anti-CD3 (Santa Cruz Biotechnology Inc., 1:2000); CD11c (BD Pharmingen, 1:500); and CD11b (Invitrogen, 1:1000). Biotinylated secondary antibodies utilized included goat anti-Armenian hamster IgG (Jackson Laboratories, 1:1000); goat anti-mouse $\mathrm{F}\left(\mathrm{ab}^{\prime}\right) 2$ (Jackson Laboratories, 1:2000); goat anti-rabbit IgG (Vector Laboratories, 1:1000); and goat anti-rat IgG (Vector Laboratories, 1:2000). Sections used for MHC II, CD11c, CD3, and Iba-1 analysis were counterstained with Methyl Green (Vector Laboratories) according to the manufacturer's protocol. For immunofluorescence, primary antibodies were utilized at concentrations three times the IHC level. Secondary antibodies bound to Alexa (Invitrogen) or DyLight (Jackson Laboratory) fluorophores were utilized at a dilution of 1:500.

\section{Cell quantification}

Profiles of eGFP+ cells were quantified in three distinct brain regions: the fimbria/fornix, corpus callosum/extreme 
capsule, and hippocampus, regions that were completely within the radiation field. Counting for this analysis began rostrally with the first section where the dentate gyrus was visible and ceased caudally with the last section containing the hippocampus. For the construction of the graph demonstrating the distribution of eGFP+ cells along the rostro-caudal axis (Fig. 3), eGFP+ cell profiles were counted on sections throughout the brain until the end of the cerebral cortex for each animal. In both of the aforementioned cases, bright-field images of the sections were captured using a RT Spot camera (Diagnostic Instruments, Inc.) using a $\times 10$ objective and were combined using the photomerge function in Adobe Photoshop CSII (Adobe Systems). Total areas for the regions examined were calculated using Image $(\mathrm{NIH})$, and the total number of cell profiles was divided by the total area in square millimeters. In the case of Fig. 3, the number of cells per square millimeter was plotted versus the approximate distance to/from bregma, which was estimated using a mouse brain atlas [46].

To quantify MHC II+, CD11c+, and CD3+ cells, sections were viewed with a Zeiss Axioplan2i light microscope (Zeiss, Thornwood, NY, USA) and the numbers of positively stained cells with a methyl green-stained nucleus were derived from the total seen in the first two brain sections containing the dentate gyrus. The total number of $\mathrm{MHC} \mathrm{II}+, \mathrm{CD} 11 \mathrm{c}+$, and $\mathrm{CD} 3+$ stained cell profiles co-localizing with a methyl green positive nucleus were also plotted for each time point. A two-way ANOVA was conducted on the values associated with each marker from both chimera animals and non-chimera animals at 6 months post-brain irradiation. When the interaction term of the two-way ANOVA was significant, Fisher's protected least significant differences post hoc tests were conducted comparing all groups.

To quantify Iba-1+ cells in the hippocampus, sections were viewed with a Zeiss Axioplan light microscope equipped with a Prior motorized stage. Morphometric data were collected using the stereological program Stereologer (Systems Planning and Analysis, Inc.) and its optical disector method for unbiased cell counting. The number of cells was reported as the total number of Iba1-positive hippocampal cells. Data were compared by an unpaired $t$ test using Prism 5.01 (GraphPad Software, www.graphpad.com). A $p$ value $<0.05$ was considered to be statistically significant.

\section{Results}

\section{Chimera creation did not affect the peripheral or CNS response to brain irradiation}

In order to determine any effect of, or interaction between, chimera induction and subsequent brain irradiation on circulating BMD cell populations, peripheral blood was collected at all time points and analyzed using
FACS. The percentage of cells expressing CD11b, B220, CD4, or CD8 (representing monocytic, B cell, and T cell lineages, respectively) and also expressing eGFP were calculated and were compared for each cell marker using a two-way ANOVA with Bonferroni post hoc tests. No significant difference in the interexperimental degree of chimerism (relative levels of bone marrow reconstitution) was seen between chimera groups alone or, importantly, between brain-irradiated versus non-brain-irradiated chimeras at any of the different time points for the majority of cell types (data not shown). The only exception was the $\mathrm{CD} 4+$ population at 3 days post-brain irradiation, when a significant, but transient, decrease in the percentage of eGFP+ cells was seen $(p<0.01)$. The transience of this response, likely an indicator of the known radiation sensitivity of CD4+ cells, was felt to be insufficient to affect the responses seen at the remaining time points.

In addition to assessing the peripheral/humoral response to chimera induction, IHC staining was performed to determine whether the inflammatory responses seen in the brains of chimeras were similar to that seen in wildtype, non-chimera animals. Staining for MHCII, CD3, and CD11c was conducted on control and 35-Gy-irradiated tissues at 6 months post-bone marrow transplant (Fig. 1). The numbers of positively stained cells for each marker in transplanted wild-type animals were compared to the numbers attained from non-transplanted wild-type animals using a two-way ANOVA. If the interaction term was significant, it was followed by Fisher's PLSD post hoc tests.

For both $\mathrm{MHC} \mathrm{II}+$ and $\mathrm{CD} 3+$ cells, the two-way ANOVA revealed no significant interaction between brain irradiation and bone marrow transplant/chimera induction (Fig. 1a, b), although a significant effect of bone marrow transplantation on MHC II+ cells $(F(1,16)=$ 6.429, $p=0.0220$ ) was found (Fig. 1a). Both MHC II+ and CD3+ cells demonstrated a significant effect of brain irradiation $(F(1,16)=263.026, p<0.0001 ; F(1,17)=26.45$, $p<0.0001$, respectively), but the fact that there was no significant difference between the number of MHC II+ or $\mathrm{CD} 3+$ cells in animals undergoing chimera induction followed by brain irradiation versus those undergoing brain irradiation alone suggests little to no additive effect from chimera induction.

Statistical analysis of CD11c+ cell numbers revealed a significant effect from the chimera induction/BMT protocol $(F(1,16)=13.42, p=0.002)$, a significant effect of brain radiation exposure $(F(1,16)=37.99, p<0.0001)$, and also a significant interaction effect $(F(1,16)=9.369$, $p=0.0075$ ) (Fig. 1c). However, since the number of CD11c+ cells was significantly different between the chimera/BMT and non-chimera control groups, the fold change in $\mathrm{CD} 11 \mathrm{c}+$ cells was calculated for irradiated mice with respect to their controls for both conditions to determine 


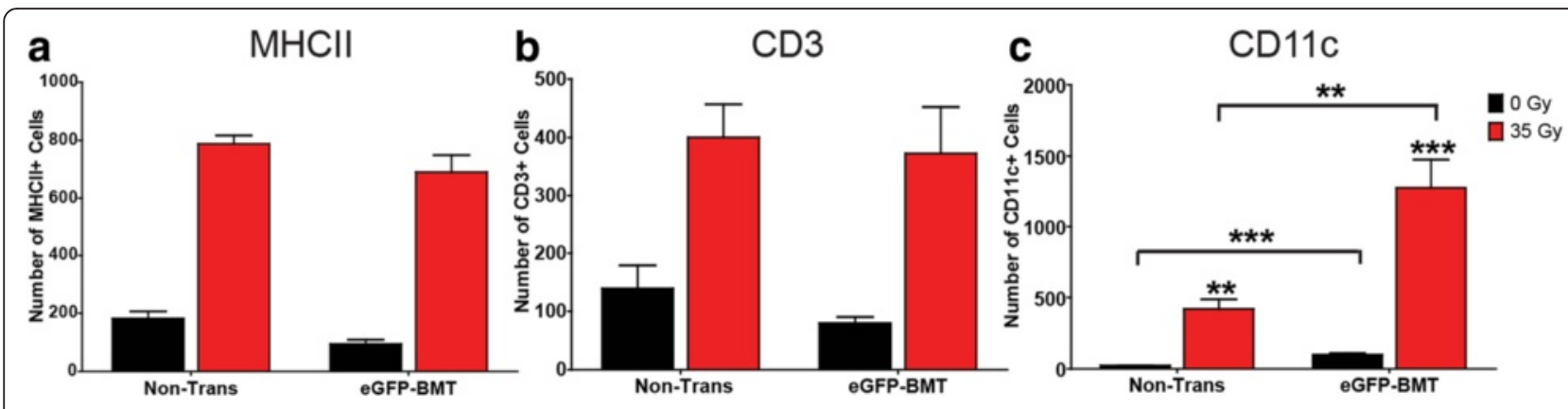

Fig. $1 \mathrm{IHC}$ analysis of immune cell markers in eGFP chimeras at 6 months following brain irradiation. To determine if the radiation component of chimera induction altered the presence of immune markers seen following brain irradiation in wild-type animals, 0- and 35-Gy brain-irradiated eGFP chimera (bone marrow transplant: eGFP-BMT) and non-chimera (Non-Trans) animals were analyzed for a MHCII+, b CD3+, and c CD11c+ cells at 6 months post-irradiation. The numbers of positively stained cells quantified in the first two sections containing the dentate gyrus as described in the Methods section were compared using a two-way ANOVA with Fisher's protected least significant (PLSD) post hoc tests comparing all conditions. Graph bars represent mean \pm SEM, $n=4-6$ mice per condition: ${ }^{* *} p \leq 0.01$ and ${ }^{* * *} p \leq 0.001$

whether the CD11c response to brain irradiation differed between the two sets of animals. An unpaired $t$ test found that the fold change in the number of CD11c+ cells following brain irradiation between non-chimera $(M=17.7$, $\mathrm{SD}=2.87)$ and chimera animals $(M=12.69), t(9)=1.469$, $p=0.1760)$ did not reach statistical significance, supporting our contention that the irradiation component of chimera induction did not affect the overall cell response to brain irradiation.

\section{Brain irradiation induced dose-dependent, delayed infiltration of bone marrow-derived cells}

To provide a detailed characterization of the effect of CNS irradiation on the observed recruitment of peripherally derived immune cells to the brain, chimeras were administered brain irradiation (0 or 35 Gy) and sacrificed at multiple time points. Initial observation of tissues showed no evidence of eGPF+ cell infiltration at early time points, but clear evidence of infiltration at later time points (Fig. 2a, b). Images were constructed to illustrate the distribution of recruited cells at these later time points (Fig. 2c), similar to our previously reported findings [3]. Based on these findings, the number of eGFP + cells per square millimeter was quantified across all time points for three distinct brain regions, two white matter and one gray matter: (1) the fimbria/fornix, (2) corpus callosum and extreme capsule, (3) and hippocampus, respectively (Fig. 2d). At 1 month post-radiation, an increase in the numbers of cells per square millimeter was seen in all brain regions, although statistical significance was only achieved in the hippocampal region $(45 \pm 40$ vs. $1 \pm 1, p<0.01)$. However, by 3 months post-radiation, a statistically significant increase in the number of eGFP+ cells per square millimeter was seen in all brain regions, with the density increasing further at 6 months (Fig. 2d). The data were analyzed using two-way ANOVA with Bonferroni post hoc tests comparing brain-irradiated chimeras to controls at each time point. Significant effects of brain radiation exposure $(p=0.001, p<0.0001$, and $p<$ 0.0001 ), effects of time (age post-radiation) ( $p=0.005, p<$ 0.0001 , and $p<0.0001$ ), and effects of interaction between brain irradiation and time $(p=0.007, p<0.0001$, and $p<$ 0.0001 ) were found in the fimbria/fornix, corpus callosum/extreme capsule, and hippocampal regions, respectively. Interestingly, the majority of eGFP+ cells observed exhibited microglial morphology, and the infiltration pattern showed a rostro-caudal distribution, with little evidence of infiltration in the extreme rostral or caudal sections.

To determine the effect of dose on infiltration, the study was repeated using a range of brain irradiation doses (5-45 Gy). At 6 months post-radiation, the number of eGFP+ cell per square millimeter was again quantified for the three brain regions and analyzed using one-way ANOVA with Bonferroni post hoc tests, and comparisons were performed between all doses (Fig. 2e). Significant differences in the number of infiltrating cells were found with respect to radiation dose in the fimbria/ fornix region $(F(5,24)=14.77, p<0.0001)$, the corpus callosum/extreme capsule region $(F(5,24)=20.16$, $p<0.0001)$, and the hippocampus $(F(5,24)=13.22$, $p<0.0001)$. Post hoc test analysis revealed that brain irradiation resulted in dose-dependent increases in cell infiltration in all brain regions, which reached significance $\geq 25$ Gy, although infiltration was clearly evident at 15 Gy (Fig. 2e).

\section{Direct radiation exposure is required for peripherally derived immune cell recruitment into CNS}

As is often recognized clinically, the radiation-induced injury seen in this study, defined by upregulation of activation and immune markers, areas of increased staining and altered morphology, was limited to the tissue volume directly exposed to the radiation beam. This pattern 


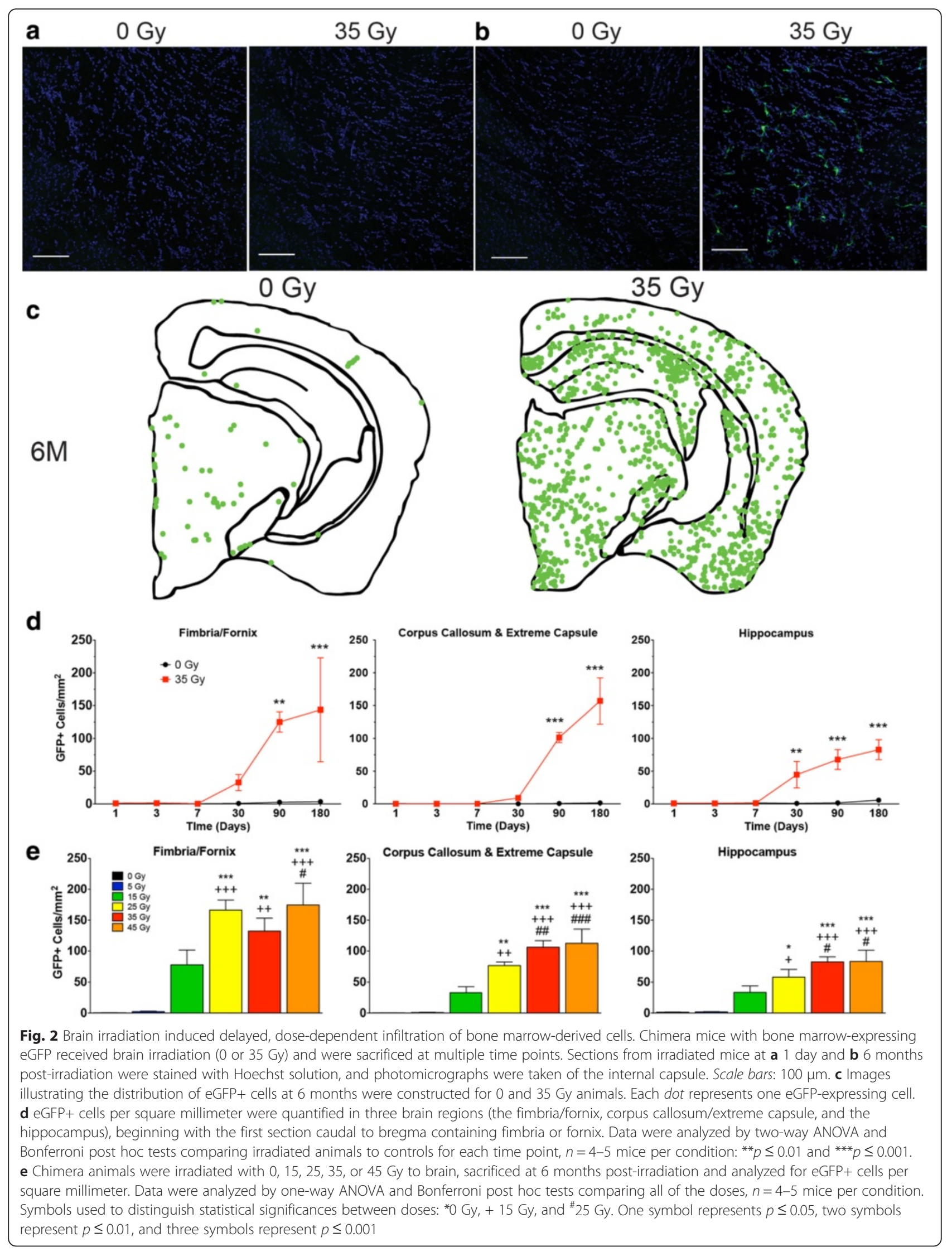


of response appeared to be repeated with respect to inflammatory cell infiltration since the rostral striatum, which was shielded by the irradiator collimator, failed to demonstrate cellular infiltration at any dose compared to the internal capsule, which was within the radiation beam (Fig. 3a). To better establish whether the directly injured tissue selectively influenced the influx of peripherally derived immune cells, a profile of eGFP+ cells was established from a 1:24 series of brain tissue sections from 0- or 45-Gy-irradiated animals. The number of cells per square millimeter was plotted versus the location relative to bregma of the quantified tissue section (Fig. 3b); locations were estimated using a mouse brain atlas [46]. In the control (non-brain irradiated) chimera animals, the number of cells per square millimeter did not change significantly between tissue sections along the rostro-caudal axis, regardless of position in relation to bregma. Furthermore, the quantification of tissue sections from non-irradiated chimeras indicated only $\leq 3$ eGFP + cells per square millimeter. In contrast, sections from 45-Gy brain-irradiated chimera animals exhibited a greater range of values $\left(1-121\right.$ cells $\left./ \mathrm{mm}^{2}\right)$, with every animal assessed exhibiting a similar pattern regarding cell number change (increase, plateau, then decrease) along the rostro-caudal axis. Although the position of the peak response varied along the axis, the distance over which the change in cell numbers occurred was observed as being relatively similar (within approximately 7-8 brain sections). To confirm this observation, Fig. $3 \mathrm{~b}$ was re-plotted, using the tissue section that showed the greatest infiltrate per square millimeter as section 0 (Fig. 3c). Since the sections were cut at $30-\mu \mathrm{m}$ intervals and mounted 1:24, multiplying the number of sections over which the number of eGFP+ cells was greater than that of controls yielded a radiation-responsive distance of $5.04-5.76 \mathrm{~mm}$, relatively close to the anticipated volume of radiation injury from a $5-\mathrm{mm}$ slit, the exact size of the collimator utilized in our model, plus the additional injury due to Bremsstrahlung radiation.

Bone marrow-derived cells express CD11C, MHC II, CD11b, and CD3 in irradiated brain

To further characterize radiation-induced myeloid cell recruitment and determine their contribution to the observed neuroinflammatory response, sections from chimera animals exposed to 0 versus 35 Gy brain irradiation at six months post-radiation were stained for eGFP and the immune marker, CD11b. Visual examination revealed that a large proportion of the eGFP+ cells colabeled with CD11b, indicating recruitment of cells of

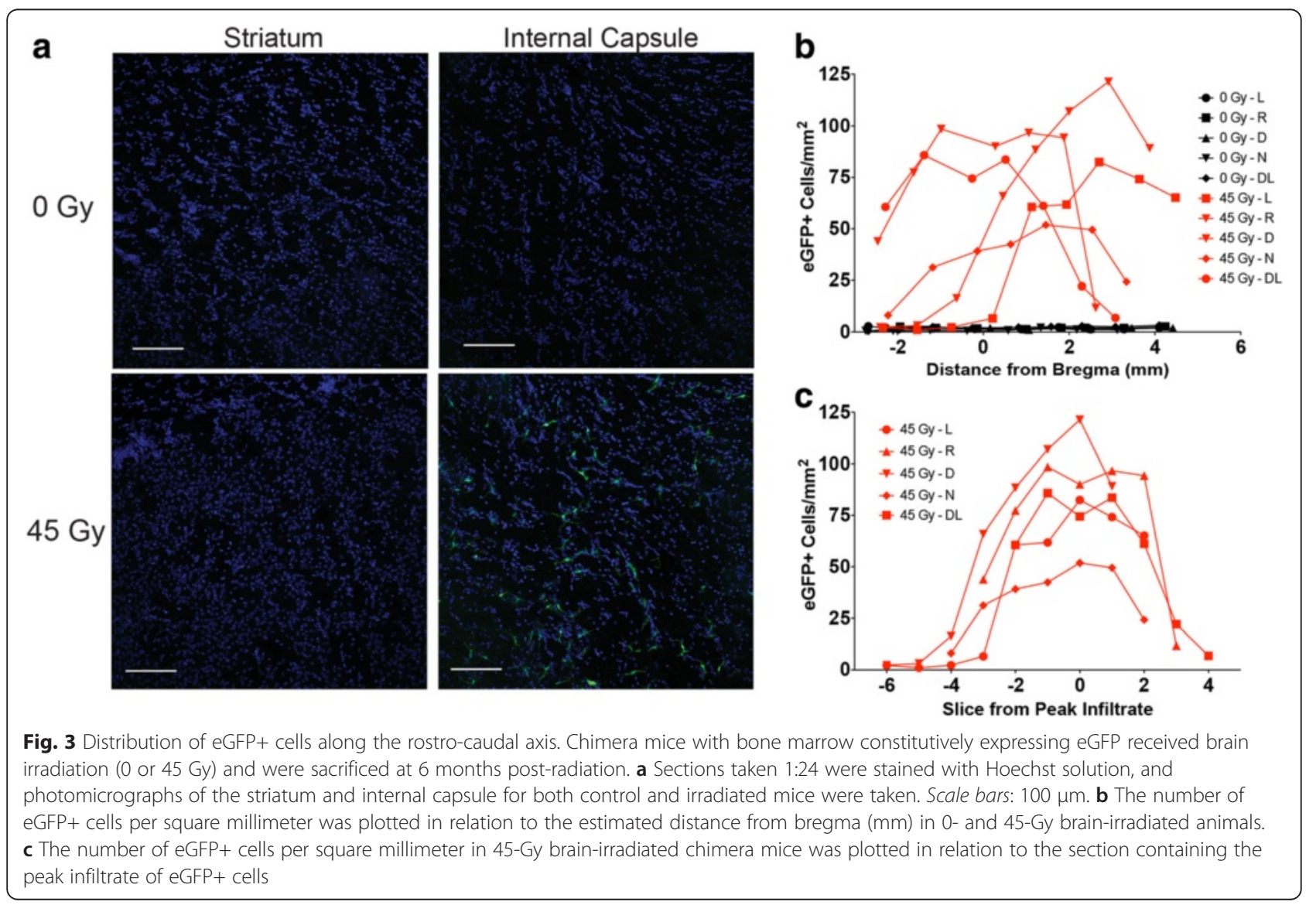


myeloid origin (Fig. 4a), although independent staining for MHC II, CD3, and CD11c confirmed the recruitment of infiltrating cells of multiple phenotypes into the brain parenchyma (Fig. 4b-d), as was reported in our previous study [3]. To determine any interaction between these various cell populations, additional co-localization studies were performed (Fig. 5). Cells co-expressing eGFP with $\mathrm{MHC}$ II and CD11c were seen adjacent to cells expressing MHC II and CD11c only, suggesting that the inflammatory population was comprised of both endogenous and peripheral cells.
Based on the cell profile density, the average number of infiltrating cells in the hippocampus at 6 months post-radiation was calculated to be $\sim 34.3 \times 10^{3}$ cells. To determine if this recruitment resulted in an increase in the total number of myeloid cells, sections from 0 and 45 Gy exposed animals at 6 months post-radiation were stained for Iba- 1 and the number of Iba-1+ cells in the hippocampus was quantified using unbiased stereology. Although there was a clear difference in morphology and staining intensity between control and irradiated tissues (Fig. 6a), an unpaired $t$ test revealed no significant

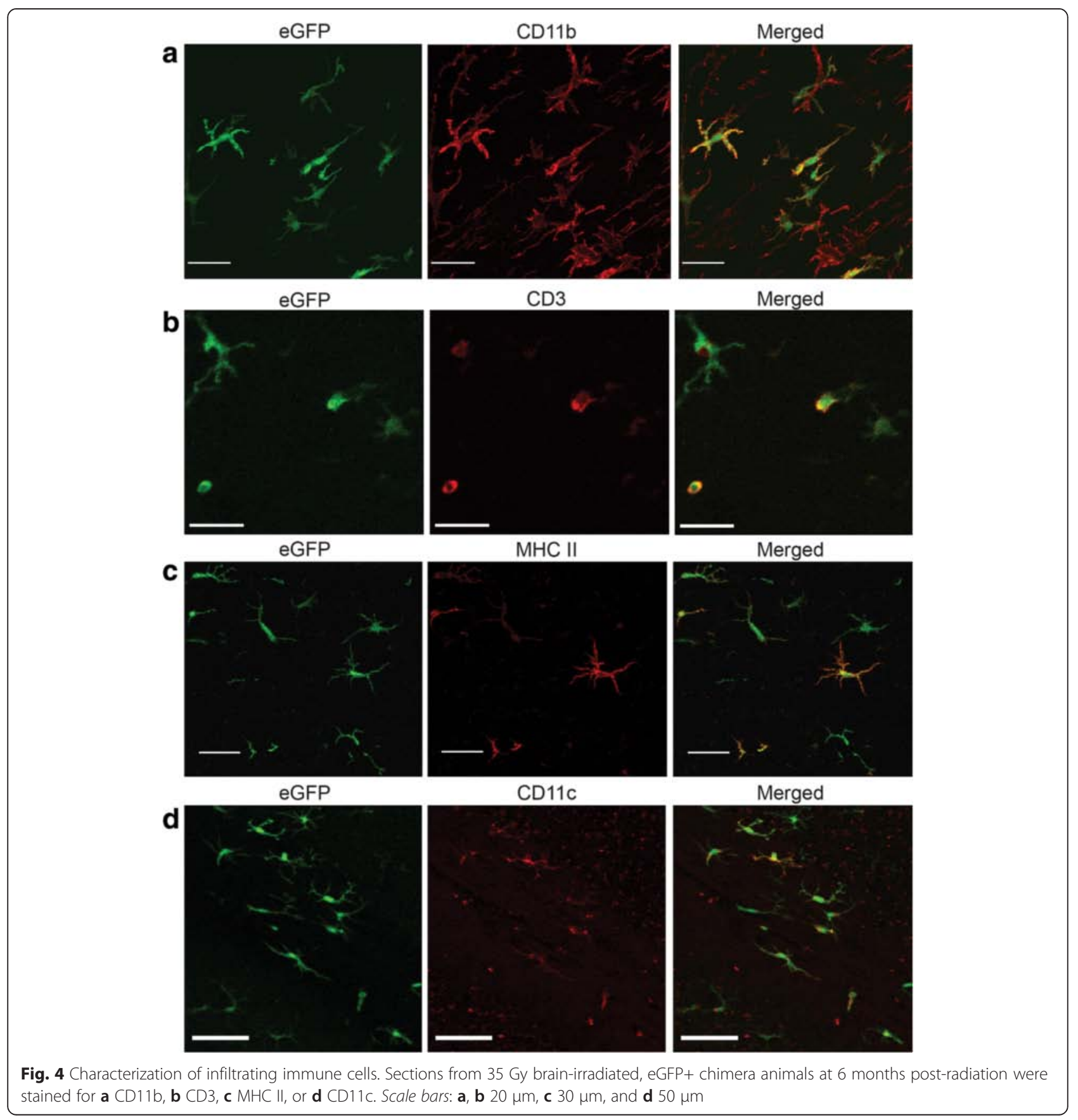




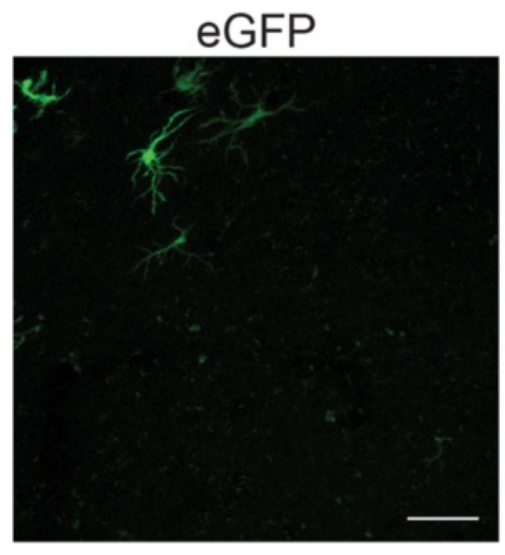

CD11c

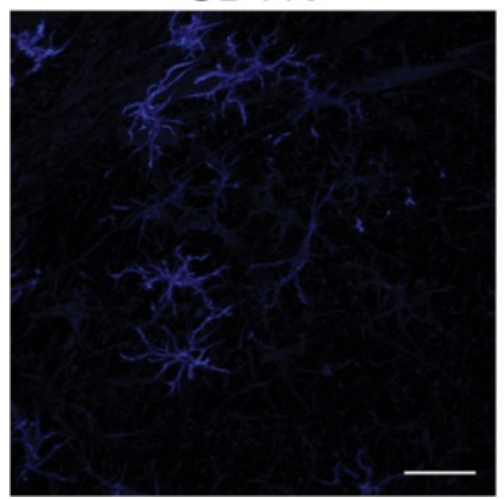

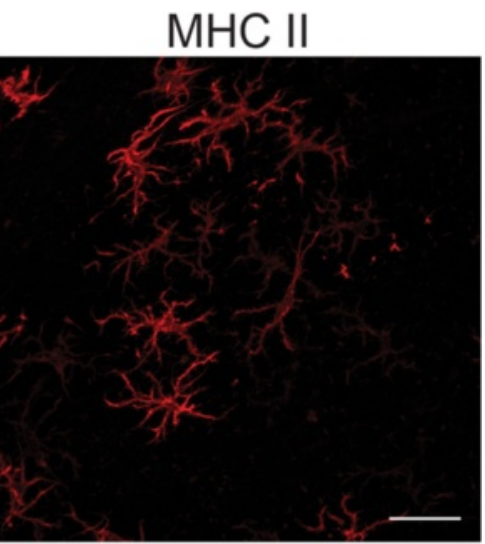

Merge

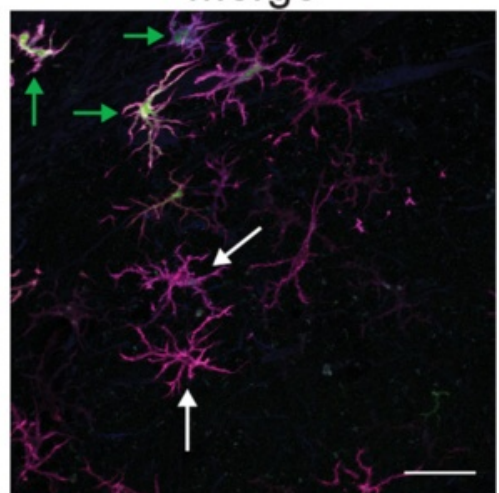

Fig. 5 Brain irradiation resulted in the recruitment of CD11c+/MHC II+ cells. Sections from 35 Gy brain-irradiated eGFP+ chimera animals at 6 months post-radiation were stained for MHC II and CD11C. Co-localization of markers were seen in eGFP-negative, endogenous cells (white arrows) as well as eGFP+ peripherally derived cells (green arrows). Scale bars: $100 \mu \mathrm{m}$

difference in the total number of microglial/myeloid cells between brain-irradiated animals and controls in the hippocampus at this time point (Fig. 6b), suggesting that the infiltrating cells had replaced, but not added to, the population of microglial resident cells.

\section{Radiation-induced recruitment of peripherally derived myeloid cells is dependent on CCR2 signaling}

As noted, we had observed that the majority of infiltrating cells following brain irradiation appeared to display a microglia- or myeloid-like morphology (Figs. 5 and 6). CCR2 is a chemokine receptor recognized as playing a critical role in the recruitment of monocyte cells in various disease models [47]. Previous work from our laboratory demonstrated early and late increases for CCR2's primary ligand, CCL2 (MCP-1) $[1,3]$. To examine the role of CCL2/CCR2 signaling in immune cell recruitment seen following brain irradiation, animals deficient for CCR2, but constitutively expressing eGFP under the $\beta$-actin promoter, served as donors for chimera studies. Following confirmation of chimerism, animals were exposed to 0 or 35 Gy brain irradiation and sacrificed at 6 months post-irradiation. The numbers of eGFP+ cells in the eGFP+ CCR2-null chimeras were quantified in the three regions of interest in the brain and compared to eGFP+ CCR2+ animals utilizing two-way ANOVAs, followed by Fisher's PLSD post hoc tests comparing all groups (Fig. 7a). Importantly, transplant efficiencies analyzed by two-tailed, unpaired $t$ test for the eGFP+ CCR2null versus eGFP+CCR2 + chimera animals showed no significant difference in the percentage of eGFP+ CD45+ cells in peripheral blood between the two sets of transplanted animals.

Analysis of area-specific infiltrating $(\mathrm{eGFP}+)$ cells in the eGFP+, CCR2-null chimeras at 6 months postradiation (Fig. 7a) showed a significant interaction effect $(F(1,17)=5.15, p=0.04 ; F(1,17)=43.69, p<0.0001 ; F(1$, $17)=17.24, p=0.0007)$ and a significant effect of brain irradiation $F(1,17)=41.56, p<0.0001 ; F(1,17)=73.83$, $p<0.0001 ; F(1,17)=30.30, p<0.0001)$ in the fimbria/ fornix, corpus callosum and extreme capsule, and hippocampus, respectively, as would be anticipated, but also demonstrated a significant effect of bone marrow genotype $(F(1,17)=6.61, \quad p=0.02 ; \quad F(1,17)=46.08, p<$ $0.0001 ; F(1,17)=23.70, p=0.0001)$. No significant difference in the number of eGFP+ cells per square 

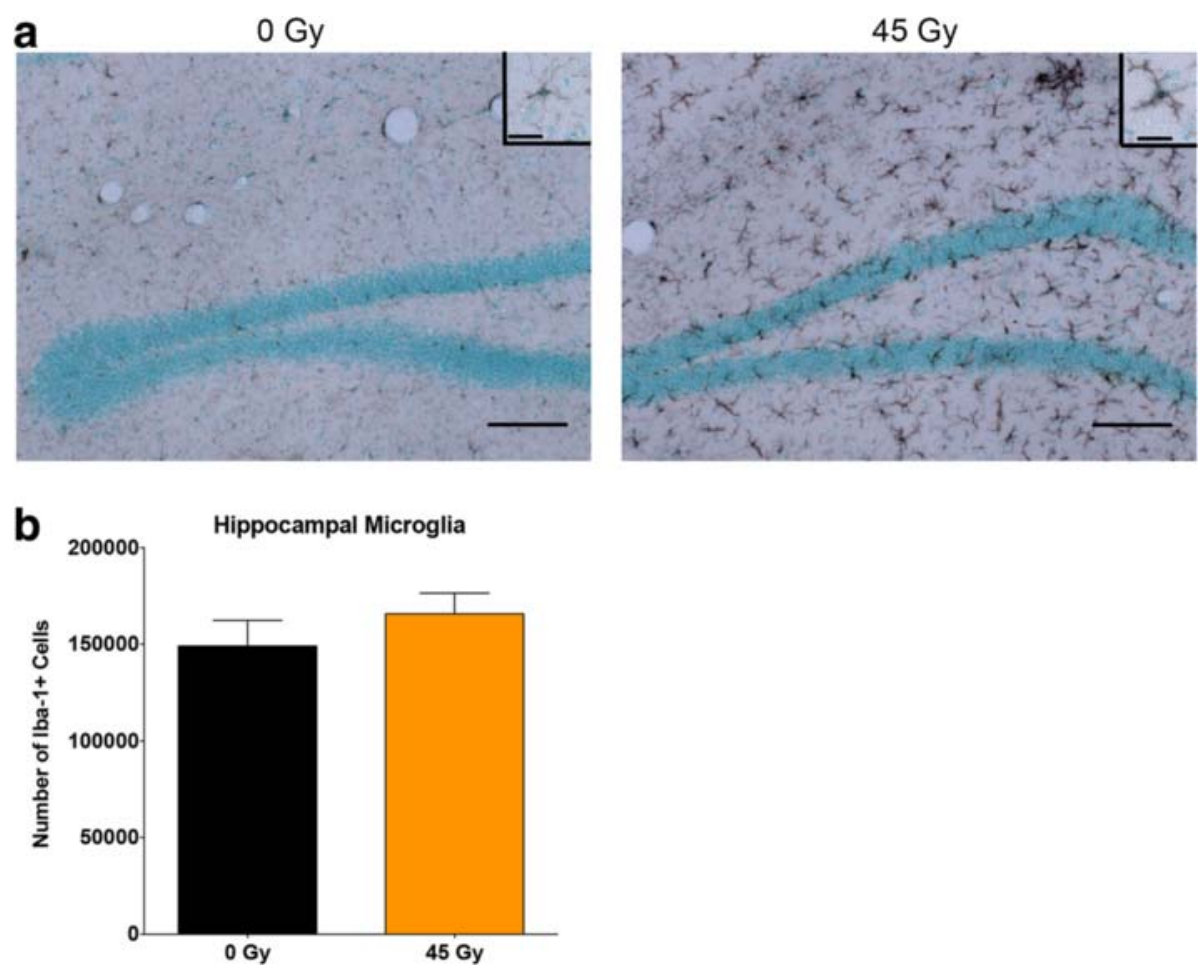

Fig. 6 Stereologic quantification of hippocampal myeloid cells in 0 and 45 Gy brain-irradiated, eGFP+ chimera mice at 6 months post-irradiation. a Sections from eGFP chimeras at 6 months following 0 or 45 Gy brain radiation were stained for lba-1 and counterstained for methyl green (Vector Laboratories). Scale bars: $100 \mu \mathrm{m}$; inset, $20 \mu \mathrm{m}$. b Graphical representation of the total number of Iba-1+ cells in the hippocampi of 0 and 45 Gy brain-irradiated chimeras. The average numbers of cells were compared using a two-tailed $t$ test. Graph bars represent mean \pm SEM, $n=6$ mice per condition

millimeter was found between CCR2+ and CCR2-null 0 Gy control animals in any of the regions of interest, indicating that there was no baseline effect on recruitment. However, post hoc test analysis showed a significant difference in the number of eGFP+ cells per square millimeter between genotypes in all areas of interest $(p=0.05,0.003$, and 0.002 for the fimbria/fornix, corpus callosum and extreme capsule, and hippocampus, respectively) following irradiation, with a significant decrease in the number of eGFP+ cells seen in all areas of interest in the CCR2-null chimeras, suggesting that CCR2 signaling does indeed play a role in radiation-induced cellular recruitment to the CNS (Fig. 7a).

To investigate whether CCR2 deficiency had a differential effect on the radiation-induced recruitment of the specific immune cell types in the brain, tissue sections from irradiated and control eGFP+ CCR2-null chimeras were stained for $\mathrm{CD} 3, \mathrm{CD} 11 \mathrm{c}$, and $\mathrm{MHC}$ II, quantified and compared to eGFP+ CCR2+ animals. Data were analyzed by two-way ANOVA, followed by Fisher's PLSD post hoc tests comparing control and brain-irradiated animals at 6 months post-radiation (Fig. 7b). Analysis of the CD3+ cells demonstrated a significant effect of radiation exposure $(F(1,15)=49.93, p<0.0001)$, but no significant effect with respect to marrow genotype, suggesting that radiation-induced $\mathrm{T}$ cell infiltration was independent of CCR2 signaling. Analysis of the number of $\mathrm{CD} 11 \mathrm{c}+$ cells also showed a significant effect of brain irradiation $(F(1,15)=109.0, p<0.0001)$ but no significant interaction effect or effect of marrow genotype. However, using an unpaired, two-tailed $t$ test with Welch's correction to compare the number of CD11c+ (resident) cells to CD11c+ cells showing co-localization with eGFP $+(\mathrm{BMD} /$ recruited $)$ revealed a significant reduction in the number of recruited CD11c+ cells in the eGFP+ CCR2-null chimeras $(M=284.0, \mathrm{SD}=48.6)$ compared to the eGFP+ CCR $2+$ chimeras $(M=773.5, \quad \mathrm{SD}=164.4)$ $(t(4)=2.856, p=0.0461)$ despite the overall total numbers of CD11c+ cells remaining the same. These findings strongly suggest that CCR2 signaling plays a role in the recruitment of myeloid CD11c+ cells to the brain following irradiation, but that, in the absence of CCR2 signaling, compensatory mechanisms allow for amplification of the resident microglial $(\mathrm{CD} 11 \mathrm{c}+)$ population.

Analysis of the MHC II+ cells suggest that a slightly different CCR2-related response was elicited in this cell population, with a significant effect now being seen on total cell numbers with respect to marrow genotype 


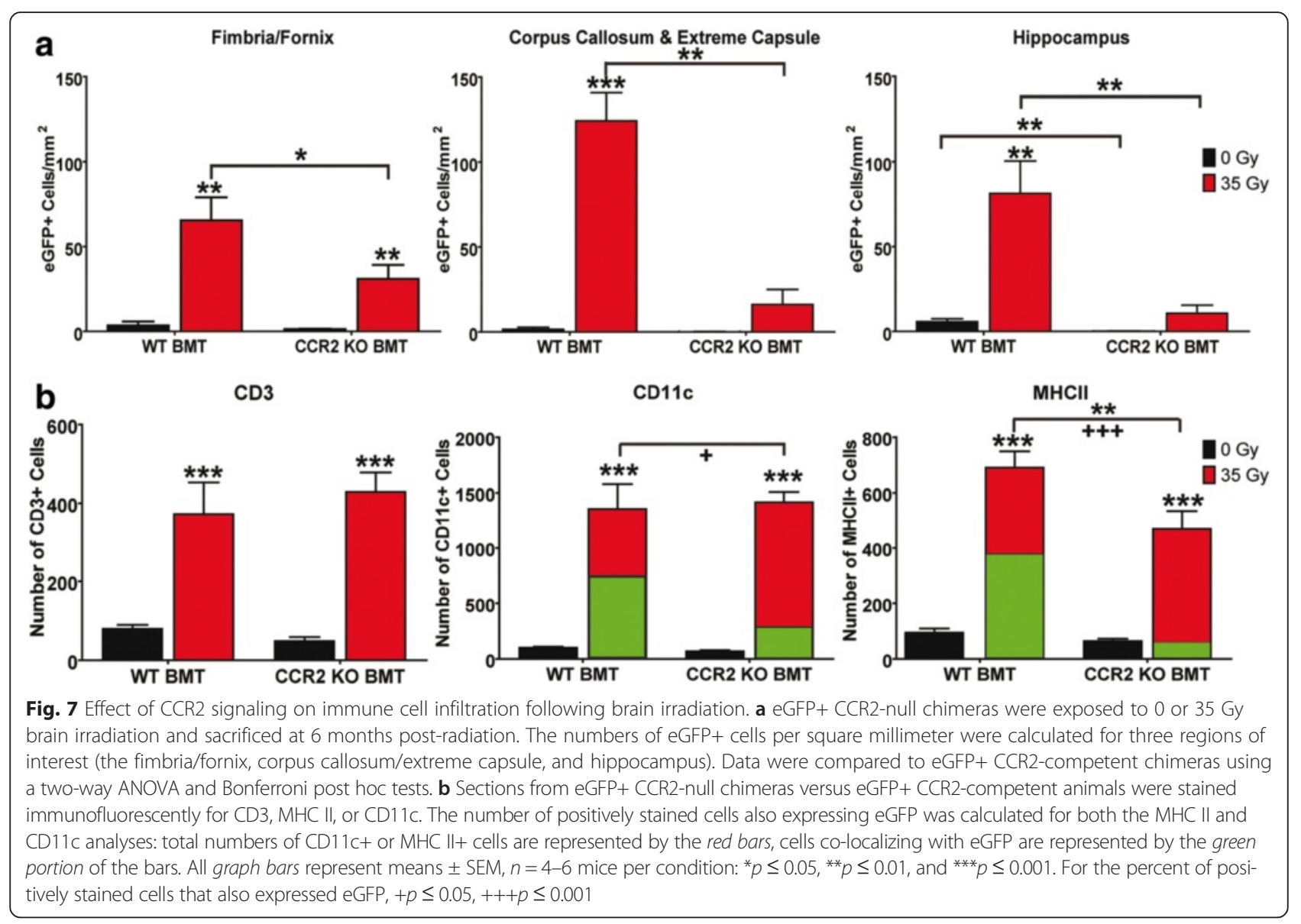

$(F(1,17)=8.59, p=0.009)$. Post hoc testing, using Fisher's PLSD, showed a significant decrease in the number of $\mathrm{MHC}$ II+ cells following brain irradiation in the CCR2null chimeras $(p=0.0023)$ (Fig. 7b). In addition, further analysis by unpaired, two-tailed $t$ test with Welch's correction again revealed a decrease in the number of $\mathrm{MHC}$ II+, eGFP+ cells in the eGFP+ CCR2-null chimeras $(M=57.9$, $\mathrm{SD}=18.9)$ relative to the eGFP+CCR2+ animals $(M=$ $381.8, \mathrm{SD}=40.9)(t(5)=7.190, p=0.0008)$. As had been seen with respect to the CD11c+ cells, these findings suggest that CCR2 signaling also plays a role in the recruitment of MHC II+ cells to the brain following irradiation, but that compensatory mechanisms allowing for amplification of the resident MHC II+ population are less robust in the absence of CCR2 signaling.

\section{Discussion}

Earlier work from our group [3] and others [17, 31] has demonstrated that brain irradiation leads to delayed influx of peripherally derived leukocytes in the CNS that becomes apparent as early as 7 days post-irradiation. Moreover, we demonstrated the persistence of peripherally derived cells in the parenchyma out to 1 year postradiation [3]. In combination with the increased MHC II expression noted in our previous experiment, these findings led us to postulate that increased MHC II expression may result from radiation-dependent recruitment of peripherally derived myeloid cells as reported by Burrell et al. [31] and that infiltration of these cells is dependent on CCR2 signaling, which has been shown to be important for myeloid cell recruitment in other models of CNS injury [47].

The series of studies presented utilized bone marrow chimeras. Use of this model may be felt by some to confound data interpretation since irradiation is part of the induction process, adding an additional earlier radiation injury; however, our use of head shielding during the creation of chimeras appeared to effectively abrogate the cell infiltration seen in chimeras created without head shielding (Additional file 1: Figure S1). Moreover, the few eGFP+ cells observed in our control chimeric mice $\left(0.5-3\right.$ cells $\left./ \mathrm{mm}^{2}\right)$ were nearly all associated with the vasculature, which contrasts with the parenchymal location of infiltrating cells observed following brain irradiation. It also is possible that some of the differences seen in the various cell populations may have been the result of the transplantation process itself. However, there were no significant differences between the infiltrative response 
of the various cell types to brain irradiation between chimera and non-chimera animals, with the sole exception of the CD11c+ population. With respect to that population, chimeric animals were found to have increased numbers of CD11c+ cells at baseline compared to nontransplanted animals (Fig. 1c), supporting the observation of a radiation-induced recruitment of CD11c+ cells from the periphery made by Simard and Rivest [17], which increased over time. In addition, the number of CD11c+ cells in the CNS has been shown to increase with normal aging [30]. Although chimera animals in our study were typically 6 weeks older than non-chimera mice (because of the time required for bone marrow reconstitution), this relatively small difference in their ages is unlikely to account for the difference observed in CD11c+ cell density 6 months after irradiation. Importantly, all remaining comparisons were made between chimera groups.

Our studies demonstrated that radiation exposure of the brain yielded a delayed dose-dependent infiltration of peripherally derived cells that began at 1 month postirradiation and continued to 6 months (Fig. 2). The increased numbers of peripheral cells accumulating in the CNS with dose and time could be due solely to recruitment or to a combination of recruitment and proliferation; future studies using proliferative markers could help distinguish between these possibilities. Our temporal findings are consistent with those of Burrell et al. [31], although we were not able to demonstrate a significant difference in cell number at 7 days. Infiltration occurred at a brain radiation dose of $15 \mathrm{~Gy}$, but not $5 \mathrm{~Gy}$, and is consistent with observations from other laboratories showing bone marrow-derived cell infiltration in the irradiated brain with 10 and 13 Gy $[44,48]$ as well as our own experiments in unshielded chimera mice, which showed infiltration with a cumulative dose of 12 Gy (Additional file 1: Figure S1). Such doses are well within the range used for normal tissue margins in stereotactic radiosurgery $[49,50]$, but whether CNS infiltration of peripheral cells occurs with fractionated radiotherapy has not been investigated. The majority of infiltrating cells presented with a microglial phenotype and stained positively for CD11b, a marker of myeloid cells (Fig. 4a), although positive staining for other immune cell markers was also found on peripherally derived eGFP+ cells (Fig. 4b-d). The relative expression of other inflammatory markers in our study was similar to that seen by others [31], with a majority of BMD cells recruited to the CNS co-localizing with the myeloid markers CD11b, MAC3, and Iba-1. Our study also demonstrated the presence of cells staining positive for CD11c and MHC II in the brains of chimera mice following irradiation (Fig. 5). The majority of these cells were eGFP+, indicating that they were BMD. Because chimerism was incomplete, the degree to which endogenous CNS microglia were also activated to express CD11c and MHC II could not be determined.

The temporal pattern of leukocyte infiltration (Fig. 2) is consistent with the pattern of $\mathrm{T}$ cell recruitment seen in our previous study [3] and is similar to the pattern observed by Burrell et al., although they detected increased numbers of BMD cells as early as 7 days postirradiation [31], as had Morganti et al. [44]. Possible explanations for the temporal discrepancy in infiltration between those studies and the present study include the use of different mouse strains, radiation doses, methods of cell quantification, statistical analyses, and the interval between bone marrow transplantation and cranial irradiation. Nonetheless, our work provides additional evidence that a component of the brain's response to radiation injury is an accumulation of myeloid cells from the periphery that persists for up to 6 months.

Our finding that CCR2-deficient chimeras demonstrated decreased BMD cell recruitment (Fig. 7) strongly suggests that radiation-induced neuroinflammation leads to myeloid cell recruitment via a CCL2/CCR2-dependent mechanism. These findings are consistent with the results in other models of CNS injury that have demonstrated the importance of CCL2/CCR2 signaling for monocyte/ macrophage recruitment $[47,51]$. However, it is possible that the decrease in CNS infiltrating cells observed in the CCR2-deficient chimeras was due to a reduction in circulating inflammatory monocytes, since, in addition to its established role in migration of hematopoietic stem cells into tissues [40], CCR2 signaling also plays a role in migration of these cells out of the bone marrow [52, 53]. Further experiments will need to be conducted to better address this issue in the context of radiation injury.

Another possible explanation for the observed increase in BMD cell recruitment is a lack of self-renewal by endogenous microglial progenitor cells following radiationinduced damage. Despite the infiltration of peripherally derived cells following brain irradiation in this study, we did not find a significant increase in the total number of microglia in the hippocampus (Fig. 6). This is in contrast to the findings of Okonogi et al. who demonstrated increased numbers of Iba- $1+$ cells in the brain stem, basal ganglia, and cerebral cortex at 3 and 8 weeks following 13 Gy of brain irradiation [48]. One explanation for discrepancies between the two studies is that different brain areas were analyzed; the variable myeloid response to radiation in different brain regions has been described recently in rats [54]. In addition, our analysis was limited to counts at 6 months post-radiation, so it is possible that there may have been earlier increases in cell numbers that were subsequently lost; the study by Okonogi et al. only followed the animals out to 8 weeks postradiation [48]. Importantly, the overall density of BMD cells in irradiated brain reported by Okonogi is similar 
to the density of BMD cells we observed, and they represent a modest fraction of all Iba-1 labeled cells in histological sections [48]. These findings contrast with results reported by Burrell et al. who observed up to $50 \%$ replacement of microglia by BMD cells in their study [31]. This discrepancy might relate to the detection method utilized (two-photon microscopy). Further studies utilizing flow cytometry could be employed to better quantify numbers of infiltrating cells as a function of dose, time after irradiation, and brain region.

\section{Conclusions}

In summary, we have shown that peripherally derived immune cells participate in the CNS response to radiation, although their specific role is not clear. Certainly, ample evidence exists for BMD cells playing important roles in the repair of multiple forms of CNS injury, including neurodegenerative disease [55-61]. These peripherally derived cells may possess a more activated phenotype and/or act as better phagocytes than endogenous microglial cells in clearing debris or dysfunctional molecules $[17,55]$. We also demonstrated that CCR2 signaling was required for the efficient recruitment of myeloid cells to the CNS after irradiation. Interestingly, CCR2 deficiency has been shown to prevent hippocampal-dependent spatial learning and memory impairment observed after cranial irradiation [62], raising the possibility that BMD infiltrating cells might contribute to CNS dysfunction. However, other mechanisms may underlie these deficits; for example, CCL2 deletion improves recovery of neurogenesis following irradiation, and this effect was not associated with dramatic cell infiltration at the times or conditions tested [63]. A better understanding of the roles of BMD infiltrating cells and the mechanisms behind their recruitment may provide a means to exploit this phenomenon therapeutically to prevent injury and treat associated CNS diseases.

\section{Additional file}

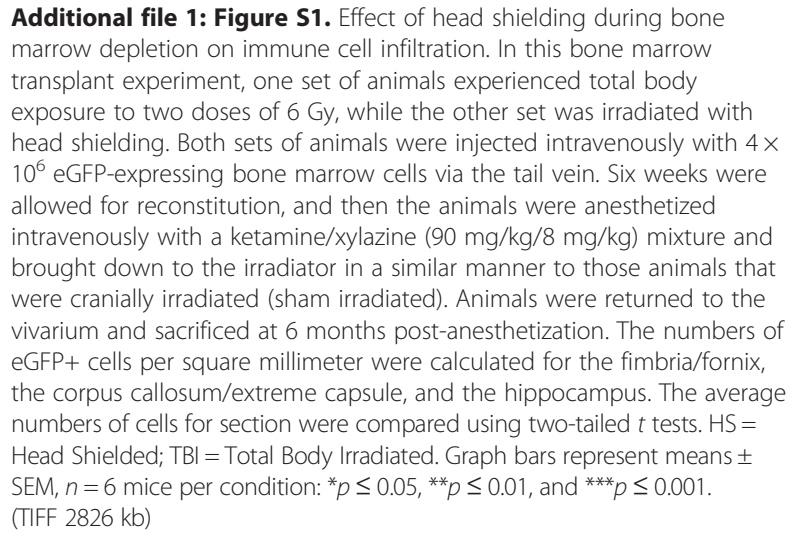

\section{Abbreviations}

B220: cluster of differentiation 45 receptor; BMD: bone marrow-derived;

CCL2: chemokine (C-C motif) ligand-2 (monocyte chemotactic protein 1); CCR2: C-C chemokine receptor type 2; CD11b: cluster of differentiation 11b (integrin, alpha M); CD11c: cluster of differentiation 11c (integrin, alpha X); CD3: cluster of differentiation 3 (T3 complex); CD4: cluster of differentiation 4; CD8: cluster of differentiation 8; CNS: central nervous system;

CX3CL1: chemokine (C-X3-C motif) ligand-1 (fractalkine); eGFP: enhanced green fluorescent protein; F4/80: EGF-like module-containing mucin-like hormone receptor-like 1 (EMR1); Gy: gray; Iba-1: ionized calcium binding adapter molecule 1; ICAM-1: intracellular adhesion molecule-1; MHC II: major histocompatibility complex, class II; PB: phosphate buffer.

\section{Competing interests}

The authors declare that they have no competing interests.

\section{Authors' contribution}

$\mathrm{MJM}, J A O, J P W$, and MKO conceived the experiments. MJM performed the experiment, data analysis, and drafted the manuscript. JPW and MKO reviewed and edited the work together with MJM and JAO. All authors read and approved the final manuscript.

\section{Acknowledgements}

The authors thank Lee Trojancyzk, Mallory Olschowka, Jack Walter, Renee Johnson, and Jamilynn Poletto for their assistance with animal irradiation and tissue preparation, Dr. Elizabeth Sorenson for her help with the flow cytometry, Dr. Sean Hurley for his guidance in quantitative RT-PCR, and Dr. Bruce Fenton for his dosimetry measurements.

Support for this work was provided by grants RO1 CA114587 from the National Institutes of Health and the Centers for Medical Countermeasures against Radiation Program, NIH/NIAID U19 grant Al091036. MJM was a trainee in the Medical Scientist Training Program funded by NIH T32 GM007356 and received support from a Training Grant in Neuroinflammation and Glial Cell Biology (T32 NS051152).

\section{Author details}

'Department of Radiation Oncology, University of Rochester School of Medicine and Dentistry, Rochester, NY, USA. ${ }^{2}$ Department of Neuroscience, University of Rochester School of Medicine and Dentistry, Rochester, NY, USA. ${ }^{3}$ Department of Environmental Medicine, University of Rochester School of Medicine and Dentistry, Rochester, NY, USA. ${ }^{4}$ Department of Neurology, University of Rochester School of Medicine and Dentistry, Rochester, NY, USA.

Received: 21 November 2015 Accepted: 26 January 2016 Received. 21 November 2015 Accepted: 26

\section{References}

1. Kyrkanides S, Moore AH, Olschowka JA, Daeschner JC, Williams JP, Hansen JT, et al. Cyclooxygenase-2 modulates brain inflammation-related gene expression in central nervous system radiation injury. Brain Res Mol Brain Res. 2002;104:159-69.

2. Moore AH, Olschowka JA, Williams JP, Paige SL, O'Banion MK. Radiationinduced edema is dependent on cyclooxygenase 2 activity in mouse brain. Radiat Res. 2004;161:153-60.

3. Moravan MJ, Olschowka JA, Williams JP, O'Banion MK. Cranial irradiation leads to acute and persistent neuroinflammation with delayed increases in T-cell infiltration and CD11c expression in C57BL/6 mouse brain. Radiat Res. 2011.

4. Ballesteros-Zebadua P, Chavarria A, Celis MA, Paz C, Franco-Perez J. Radiation-induced neuroinflammation and radiation somnolence syndrome. CNS Neurol Disord Drug Targets. 2012;11:937-49.

5. Deng Z, Sui G, Rosa PM, Zhao W. Radiation-induced c-Jun activation depends on MEK1-ERK1/2 signaling pathway in microglial cells. PLoS One. 2012; $7:$ e36739.

6. Jenrow KA, Brown SL, Lapanowski K, Naei H, Kolozsvary A, Kim JH. Selective inhibition of microglia-mediated neuroinflammation mitigates radiationinduced cognitive impairment. Radiat Res. 2013;179:549-56.

7. Kataoka T. Study of antioxidative effects and anti-inflammatory effects in mice due to low-dose X-irradiation or radon inhalation. J Radiat Res. 2013;54:587-96 
8. Mehrotra S, Pecaut MJ, Gridley DS. Minocycline modulates cytokine and gene expression profiles in the brain after whole-body exposure to radiation. In Vivo. 2014;28:21-32.

9. Parthsarathy $V$, Holscher $C$. The type 2 diabetes drug liraglutide reduces chronic inflammation induced by irradiation in the mouse brain. Eur J Pharmacol. 2013;700:42-50.

10. Chen Cl, Masih-Khan E, Jiang H, Rabea A, Cserti-Gazdewich C, JimenezZepeda VH, et al. Central nervous system involvement with multiple myeloma: long term survival can be achieved with radiation, intrathecal chemotherapy, and immunomodulatory agents. Br J Haematol. 2013;162:483-8

11. Genc M, Genc E, Genc BO, Kiresi DA. Significant response of radiation induced CNS toxicity to high dose steroid administration. Br J Radiol. 2006;79:e196-9.

12. Khan RB, Krasin MJ, Kasow K, Leung W. Cyclooxygenase-2 inhibition to treat radiation-induced brain necrosis and edema. J Pediatr Hematol Oncol. 2004;26:253-5

13. Ajami B, Bennett JL, Krieger C, Tetzlaff W, Rossi FM. Local self-renewal can sustain CNS microglia maintenance and function throughout adult life. Nat Neurosci. 2007;10:1538-43.

14. Greenwood J, Heasman SJ, Alvarez JI, Prat A, Lyck R, Engelhardt B. Review: leucocyte-endothelial cell crosstalk at the blood-brain barrier: a prerequisite for successful immune cell entry to the brain. Neuropathol Appl Neurobiol. 2011;37:24-39.

15. Meeker RB, Williams K, Killebrew DA, Hudson LC. Cell trafficking through the choroid plexus. Cell Adh Migr. 2012;6:390-6.

16. Ransohoff RM, Engelhardt B. The anatomical and cellular basis of immune surveillance in the central nervous system. Nat Rev Immunol. 2012;12:623-35.

17. Simard AR, Rivest S. Bone marrow stem cells have the ability to populate the entire central nervous system into fully differentiated parenchymal microglia. FASEB J. 2004;18:998-1000.

18. Soulet D, Rivest S. Bone-marrow-derived microglia: myth or reality? Curr Opin Pharmacol. 2008:8:508-18.

19. Vallieres L, Sawchenko PE. Bone marrow-derived cells that populate the adult mouse brain preserve their hematopoietic identity. J Neurosci. 2003;23:5197-207.

20. Mezey E, Chandross KJ, Harta G, Maki RA, McKercher SR. Turning blood into brain: cells bearing neuronal antigens generated in vivo from bone marrow. Science. 2000;290:1779-82.

21. Priller J, Flugel A, Wehner T, Boentert M, Haas CA, Prinz M, et al. Targeting gene-modified hematopoietic cells to the central nervous system: use of green fluorescent protein uncovers microglial engraftment. Nat Med. 2001;7:1356-61.

22. Kennedy DW, Abkowitz JL. Kinetics of central nervous system microglial and macrophage engraftment: analysis using a transgenic bone marrow transplantation model. Blood. 1997;90:986-93.

23. Evans TA, Barkauskas DS, Myers JT, Hare EG, You JQ, Ransohoff RM, et al. High-resolution intravital imaging reveals that blood-derived macrophages but not resident microglia facilitate secondary axonal dieback in traumatic spinal cord injury. Exp Neurol. 2014;254:109-20.

24. Hickey WF. Leukocyte traffic in the central nervous system: the participant and their roles. Semin Immunol. 1999;11:125-37.

25. Lassmann H, Schmied M, Vass K, Hickey WF. Bone marrow derived elements and resident microglia in brain inflammation. Glia. 1993;7:19-24.

26. Mildner A, Schmidt H, Nitsche M, Merkler D, Hanisch UK, Mack M, et al. Microglia in the adult brain arise from Ly-6ChiCCR2+ monocytes only under defined host conditions. Nat Neurosci. 2007;10:1544-53.

27. Mildner A, Schlevogt B, Kierdorf K, Bottcher C, Erny D, Kummer MP, et al Distinct and non-redundant roles of microglia and myeloid subsets in mouse models of Alzheimer's disease. J Neurosci. 2011;31:11159-71.

28. Mohammad MG, Tsai WW, Ruitenberg MJ, Hassanpour M, Li H, Hart PH, et al. Immune cell trafficking from the brain maintains CNS immune tolerance. J Clin Invest. 2014;124:1228-41.

29. Smolders J, Remmerswaal EB, Schuurman KG, Melief J, van Eden CG, van Lier RA, et al. Characteristics of differentiated CD8(+) and CD4 (+) T cells present in the human brain. Acta Neuropathol. 2013;126:525-35.

30. Stichel CC, Luebbert $H$. Inflammatory processes in the aging mouse brain: participation of dendritic cells and T-cells. Neurobiol Aging. 2007;28:1507-21

31. Burrell K, Hill RP, Zadeh G. High-resolution in-vivo analysis of normal brain response to cranial irradiation. PLoS One. 2012;7:e38366.
32. Angiari S, Constantin G. Selectins and their ligands as potential immunotherapeutic targets in neurological diseases. Immunotherapy. 2013;5:1207-20.

33. Olschowka JA, Kyrkanides S, Harvey BK, O'Banion MK, Williams JP, Rubin P, et al. ICAM-1 induction in the mouse CNS following irradiation. Brain Behav Immun. 1997;11:273-85.

34. Seguin R, Biernacki K, Rotondo RL, Prat A, Antel JP. Regulation and functional effects of monocyte migration across human brain-derived endothelial cells. J Neuropathol Exp Neurol. 2003;62:412-9.

35. Conductier G, Blondeau N, Guyon A, Nahon JL, Rovere C. The role of monocyte chemoattractant protein MCP1/CCL2 in neuroinflammatory diseases. J Neuroimmunol. 2010;224:93-100

36. Schilling M, Strecker JK, Ringelstein EB, Schabitz WR, Kiefer R. The role of CC chemokine receptor 2 on microglia activation and blood-borne cell recruitment after transient focal cerebral ischemia in mice. Brain Res. 2009;1289:79-84.

37. Yao Y, Tsirka SE. Monocyte chemoattractant protein-1 and the blood-brain barrier. Cell Mol Life Sci. 2014;71:683-97.

38. Kioi M, Vogel H, Schultz G, Hoffman RM, Harsh GR, Brown JM. Inhibition of vasculogenesis, but not angiogenesis, prevents the recurrence of glioblastoma after irradiation in mice. J Clin Invest. 2010;120:694-705.

39. Kozin SV, Kamoun WS, Huang Y, Dawson MR, Jain RK, Duda DG. Recruitment of myeloid but not endothelial precursor cells facilitates tumor regrowth after local irradiation. Cancer Res. 2010;70:5679-85.

40. Charo IF, Ransohoff RM. The many roles of chemokines and chemokine receptors in inflammation. N Engl J Med. 2006;354:610-21.

41. Chu HX, Arumugam TV, Gelderblom M, Magnus T, Drummond GR, Sobey CG. Role of CCR2 in inflammatory conditions of the central nervous system. J Cereb Blood Flow Metab. 2014;34:1425-9.

42. Mahad DJ, Ransohoff RM. The role of MCP-1 (CCL2) and CCR2 in multiple sclerosis and experimental autoimmune encephalomyelitis (EAE). Semin Immunol. 2003:15:23-32.

43. Sagar D, Lamontagne A, Foss CA, Khan ZK, Pomper MG, Jain P. Dendritic cell CNS recruitment correlates with disease severity in EAE via CCL2 chemotaxis at the blood-brain barrier through paracellular transmigration and ERK activation. J Neuroinflammation. 2012;9:245.

44. Morganti JM, Jopson TD, Liu S, Gupta N, Rosi S. Cranial irradiation alters the brain's microenvironment and permits CCR2+ macrophage infiltration. PLoS One. 2014;9:e93650

45. Lampron A, Lessard M, Rivest S. Effects of myeloablation, peripheral chimerism, and whole-body irradiation on the entry of bone marrowderived cells into the brain. Cell Transplant. 2012;21:1149-59.

46. Franklin KBJ, Paxinos G. The mouse brain in stereotaxic coordinates. San Diego: Academic; 1997.

47. Semple BD, Kossmann T, Morganti-Kossmann MC. Role of chemokines in CNS health and pathology: a focus on the CCL2/CCR2 and CXCL8/CXCR2 networks. J Cereb Blood Flow Metab. 2010:30:459-73.

48. Okonogi N, Nakamura K, Suzuki Y, Suto N, Suzue K, Kaminuma T, et al. Cranial irradiation induces bone marrow-derived microglia in adult mouse brain tissue. J Radiat Res. 2014;55:713-9.

49. Shaw E, Scott C, Souhami L, Dinapoli R, Bahary JP, Kline R, et al. Radiosurgery for the treatment of previously irradiated recurrent primary brain tumors and brain metastases: initial report of radiation therapy oncology group protocol (90-05). Int J Radiat Oncol Biol Phys. 1996:34:647-54

50. Shaw E, Scott C, Souhami L, Dinapoli R, Kline R, Loeffler J, et al. Single dose radiosurgical treatment of recurrent previously irradiated primary brain tumors and brain metastases: final report of RTOG protocol 90-05. Int J Radiat Oncol Biol Phys. 2000;47:291-8.

51. Wilson EH, Weninger W, Hunter CA. Trafficking of immune cells in the central nervous system. J Clin Invest. 2010;120:1368-79.

52. Engel DR, Maurer J, Tittel AP, Weisheit C, Cavlar T, Schumak B, et al. CCR2 mediates homeostatic and inflammatory release of $\mathrm{Gr} 1$ (high) monocytes from the bone marrow, but is dispensable for bladder infiltration in bacterial urinary tract infection. J Immunol. 2008;181:5579-86.

53. Serbina NV, Pamer EG. Monocyte emigration from bone marrow during bacterial infection requires signals mediated by chemokine receptor CCR2. Nat Immunol. 2006;7:311-7.

54. Hua K, Schindler MK, McQuail JA, Forbes ME, Riddle DR. Regionally distinct responses of microglia and glial progenitor cells to whole brain irradiation in adult and aging rats. PLoS One. 2012;7:e52728. 
55. Bechmann I, Priller J, Kovac A, Bontert M, Wehner T, Klett FF, et al. Immune surveillance of mouse brain perivascular spaces by blood-borne macrophages. Eur J Neurosci. 2001;14:1651-8.

56. Borlongan CV, Glover LE, Tajiri N, Kaneko Y, Freeman TB. The great migration of bone marrow-derived stem cells toward the ischemic brain: therapeutic implications for stroke and other neurological disorders. Prog Neurobiol. 2011;95:213-28.

57. Chazaud B. Macrophages: supportive cells for tissue repair and regeneration. Immunobiology. 2014;219:172-8.

58. Cohen JA. Mesenchymal stem cell transplantation in multiple sclerosis J Neurol Sci. 2013;333:43-9.

59. Francois S, Bensidhoum M, Mouiseddine M, Mazurier C, Allenet B, Semont A, et al. Local irradiation not only induces homing of human mesenchymal stem cells at exposed sites but promotes their widespread engraftment to multiple organs: a study of their quantitative distribution after irradiation damage. Stem Cells. 2006;24:1020-9.

60. McMahon EJ, Suzuki K, Matsushima GK. Peripheral macrophage recruitment in cuprizone-induced CNS demyelination despite an intact blood-brain barrier. J Neuroimmunol. 2002;130:32-45.

61. Simard AR, Rivest $S$. Neuroprotective properties of the innate immune system and bone marrow stem cells in Alzheimer's disease. Mol Psychiatry. 2006:11:327-35.

62. Belarbi K, Jopson T, Arellano C, Fike JR, Rosi S. CCR2 deficiency prevents neuronal dysfunction and cognitive impairments induced by cranial irradiation. Cancer Res. 2013;73:1201-10.

63. Lee SW, Haditsch U, Cord BJ, Guzman R, Kim SJ, Boettcher C, et al. Absence of CCL2 is sufficient to restore hippocampal neurogenesis following cranial irradiation. Brain Behav Immun. 2013;30:33-44.

\section{Submit your next manuscript to BioMed Central and we will help you at every step:}

- We accept pre-submission inquiries

- Our selector tool helps you to find the most relevant journal

- We provide round the clock customer support

- Convenient online submission

- Thorough peer review

- Inclusion in PubMed and all major indexing services

- Maximum visibility for your research

Submit your manuscript at www.biomedcentral.com/submit 